\title{
A Pragmatic Multidisciplinary Approach to Full Mouth Rehabilitation in a Young Patient with a Collapsed Dentition
}

\author{
Sitaram R Wagle
}

\begin{abstract}
This case involved a young female patient with a collapsed dentition. Posterior teeth had supraerupted in response to their missing antagonists, thus leading to a very little restorative space. Teeth wear, high lip line, thin tissue biotype, and gingival recession added to the difficulties in restoring the case. A multidisciplinary approach that combined sound principles of periodontal, endodontic, prosthodontic, and implant therapy resulted in resolving the case pragmatically, while maintaining occlusal and esthetic standards.

Keywords: Collapsed dentition, Esthetics, Implants, Multidisciplinary, Occlusion, Rehabilitation, Wear.

International Journal of Oral Implantology and Clinical Research (2018): 10.5005/jp-journals-10012-1186
\end{abstract}

Esthetic and functional restorations in a severely collapsed dentition represent a significant challenge to any restorative clinician. Posterior teeth that are supraerupted owing to an early loss of their antagonists are commonly seen in young adults without access to dentistry during childhood and adolescence. ${ }^{1}$ Such cases are majorly complicated because of the lack of a restorative space. Additionally when the clinician is faced with teeth wear, high lip line, and a thin biotype, there is a need to approach the case in a planned manner to fulfill esthetic, occlusal, and functional criteria. Diagnosis is the key to resolving such a complex case. ${ }^{2}$

The case presented in this article needed a multitude of procedures-strategic planning and implant placement, crown lengthening, intentional root canal therapy, and gingival grafting. The main aim was to achieve restorative space and develop a proper occlusal scheme to provide long-term function and esthetics. All steps were carefully coordinated, keeping in mind the patient's young age.

The case highlights the dilemma that a restorative dentist faces when confronted with almost little to no restorative space. The option is between doing crown lengthening and intentional endodontics or raising the bite. ${ }^{3}$ This case also focuses on developing a proper anterior guidance to allow posterior disclusion within the patient's envelope of function. This ensures stability of the restorations in the long term.

\section{Case Description}

A 32-year-old petite female patient (Fig. 1) was presented with the chief complaint of inability to eat. Her chief complaint in a single line was: "I am growing thin because I cannot eat. I haven't enjoyed a good meal in years". The upper left and lower right posterior teeth were supraerupted, leaving almost no space for restorations in the opposing arch (Figs 2 and 3). The upper anterior teeth showed large wear facets (Fig. 4) and there was gingival recession in the lower anterior teeth (Fig. 5). The patient was moderately emaciated and undernourished and sought to restore her lost function and esthetics. A pragmatic approach was planned to reconstruct occlusion, esthetics, and long-term function.

\section{Risk Assessment Periodontal}

The examination revealed average dental hygiene except for a deep pocket of about $6 \mathrm{~mm}$ on the mesial of tooth no. 2 . The rest of the
Private Practice, Toothkraft, Odeon Shopping Centre, Vallabh Baug Lane, Ghatkopar (E), Mumbai, Maharashtra, India

Corresponding Author: Sitaram R Wagle, Private Practice, Toothkraft, Odeon Shopping Centre, Vallabh Baug Lane, Ghatkopar (E), Mumbai, Maharashtra, India, Phone: +91 9324780590, e-mail: drsanketw8@ gmail.com

How to cite this article: Wagle SR. A Pragmatic Multidisciplinary Approach to Full Mouth Rehabilitation in a Young Patient with a Collapsed Dentition. Int J Oral Implantol Clin Res 2018;9(1-3):60-66.

Source of support: Nil

Conflict of interest: None

teeth showed optimal alveolar bone levels. The patient had a very thin gingival biotype with high gingival scallops. Miller's class II recession was seen on the lower anterior teeth.

\section{Risk: Low}

\section{Biomechanical}

Moderate wear was seen on almost all teeth, except lower anterior teeth, which presented very mild incisal facets. Mild class III cavities were present on teeth 7,8,9, and 10; tooth nos. 16,18 and 32 had class II

(c) The Author(s). 2018Open Access This article is distributed under the terms of the Creative Commons Attribution 4.0 International License (https://creativecommons. org/licenses/by-nc/4.0/), which permits unrestricted use, distribution, and non-commercial reproduction in any medium, provided you give appropriate credit to the original author(s) and the source, provide a link to the Creative Commons license, and indicate if changes were made. The Creative Commons Public Domain Dedication waiver (http://creativecommons.org/publicdomain/zero/1.0/) applies to the data made available in this article, unless otherwise stated. 


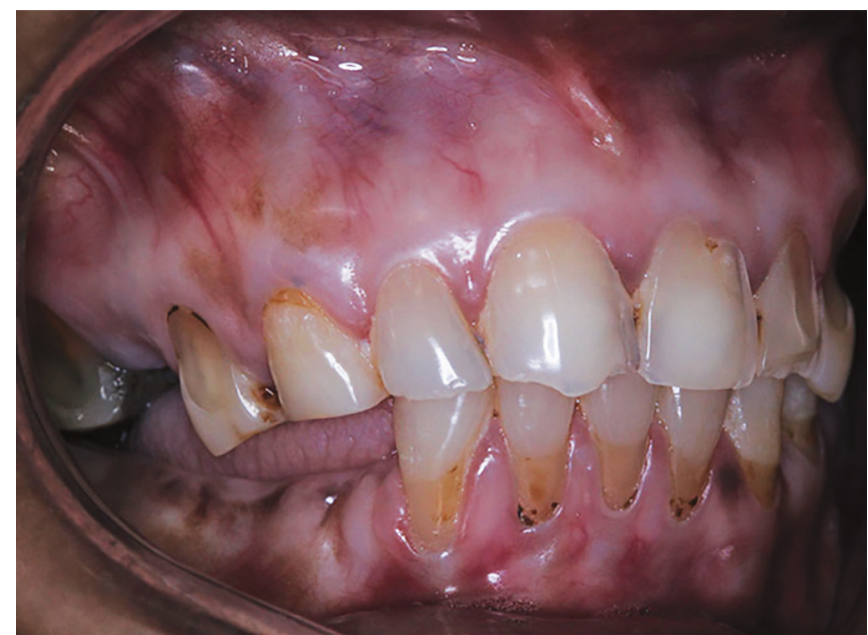

Fig. 2: Right lateral view showing supraerupted upper posterior teeth with a very little restorative space in the opposing arch

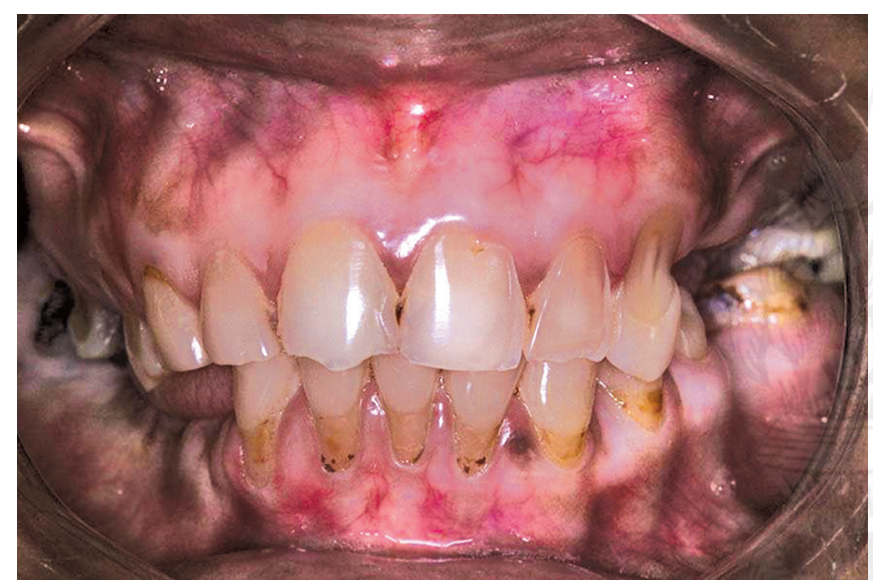

Fig. 4: Full frontal retracted view

cavities. Teeth no. 3 and 31 were endodontically treated and had huge restorations. They were deemed to be structurally compromised, with tooth no. 31 having almost no coronal tooth structure.

Risk: Moderate

\section{Functional}

The patient had supraerupted upper right posterior teeth and lower left posterior teeth. This led to an uneven occlusal plane. In the absence of posterior teeth, the mandible seemed to shift ahead in a 'hit and slide' manner. All teeth from 2 to 11 showed moderate wear on both labial and palatal aspects. Tooth no. 18 showed moderate occlusal wear. The functional diagnosis was determined to be loss of occlusal scheme, leading to generalized wear. ${ }^{3}$ However there was no muscle tenderness on palpation. Load and resistance tests were normal. The joints demonstrated no clicking or crepitus. There was no deviation on opening and the range of motion was within acceptable limits.

Risk: High

\section{Dentofacial}

The patient showed a high lip line while smiling due to slight vertical maxillary excess (Fig. 6). Tooth no. 11 had supraerupted and had a significant cant. It displayed mild gingival recession. The smile

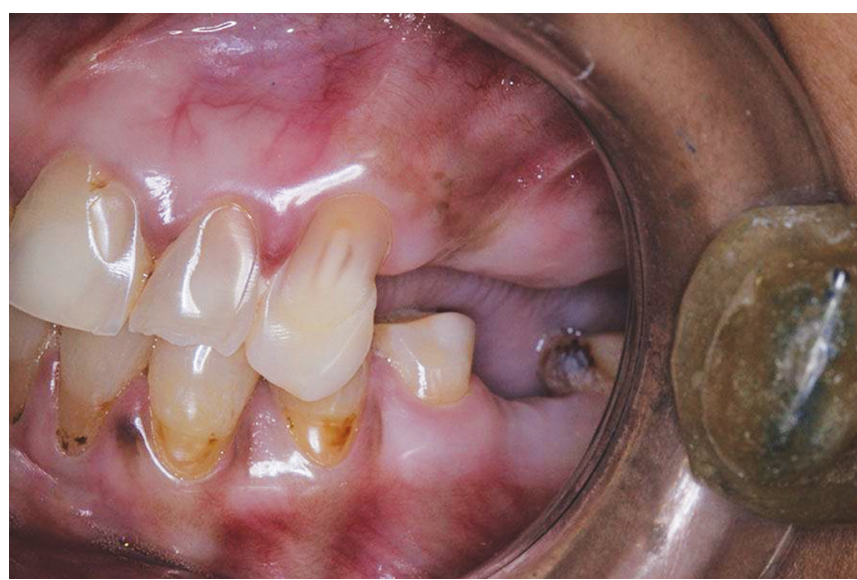

Fig. 3: Left lateral view showing supraerupted teeth nos. 18 and 20 with a very little restorative space in the opposing arch

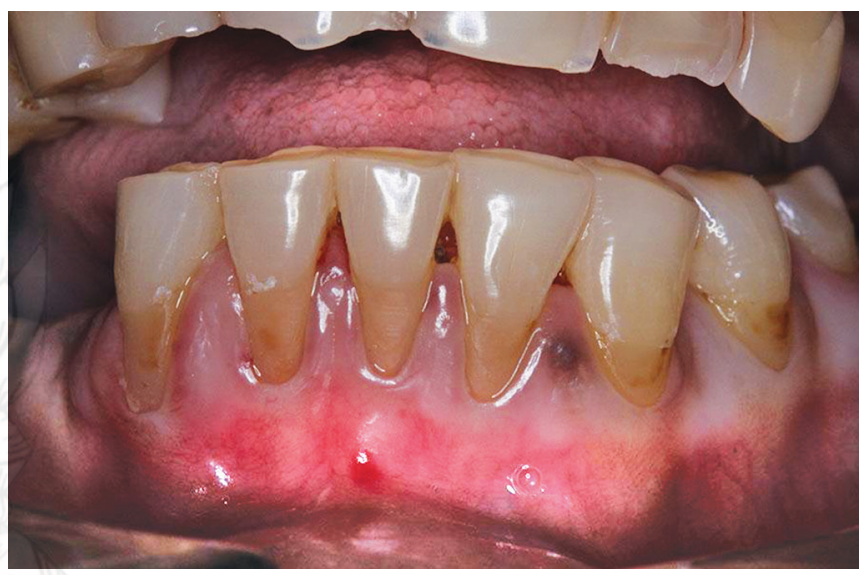

Fig. 5: Recession in lower anterior teeth

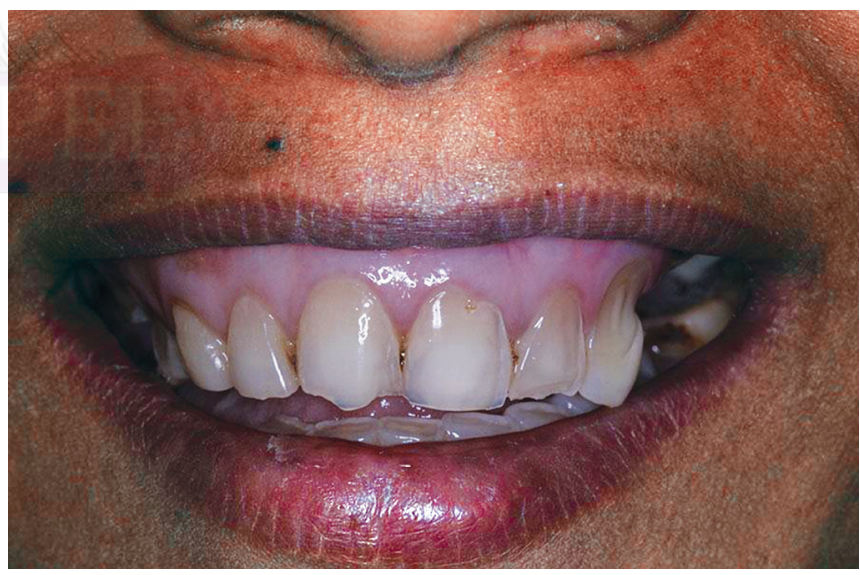

Fig. 6: Full smile, pretreatment

line was uneven. Wear facets on labial as well as palatal surfaces of teeth, uneven gingival levels, and an uneven maxillary plane were all significant findings in this evaluation. Tooth no. 9 presented with a labial-cervical-vertical groove (LCVG), which is prevalent in about $4.5 \%$ of the population. ${ }^{4}$ Yet the patient did not have any high esthetic expectation.

Risk: Moderate 


\section{TREATMENT}

\section{Options}

Orthodontics is the best noninvasive solution to intrude supraerupted teeth. ${ }^{5}$ Orthodontic alignment for the canted tooth no. 11 with a connective tissue graft would have achieved better gingival levels. However, the patient refused an extra surgical procedure and was not ready for this lengthy mode of orthodontic correction. This left us with the option of doing surgical crown lengthening to achieve two goals: first, to correct the occlusal plane; second, to achieve adequate restorative space in the antagonist arch. However, the vitality of few teeth would have to be sacrificed for this. The patient was made to understand the rationale behind the choice of this treatment plan.

Implants could have been placed for teeth no. 4 and 19. However, the patient opted to go with bridges to stay within her budget plan.

\section{Plan}

Equipped with correct diagnosis and risk assessment, an interdisciplinary approach was presented to the patient. In summary, the treatment sequence was as follows:

- Thorough prophylaxis and restorations.

- Implant placement in the areas of missing teeth.

- Crown lengthening with osseous resection in the upper right and lower left quadrants.

- Intentional root canal therapy in supraerupted teeth.

- Developing occlusion maintaining the same vertical dimension.

- PFM restorations posteriorly.

- E-max crowns in upper anterior teeth.

- Free gingival graft in the lower anterior teeth.

\section{Steps}

\section{Prophylaxis and Restorations}

A thorough scaling, polishing, and root planning was done for all teeth and the patient was put on a rigorous oral hygiene regime. The silver filling in tooth no. 3 was replaced with a composite restoration.

\section{Planning}

Mounted diagnostic casts, photographs, a full mouth series of IOPA X-rays, and a panoramic X-ray was taken ${ }^{3}$ (Fig. 7). These were used to predetermine the exact amount of osseous resection that needed

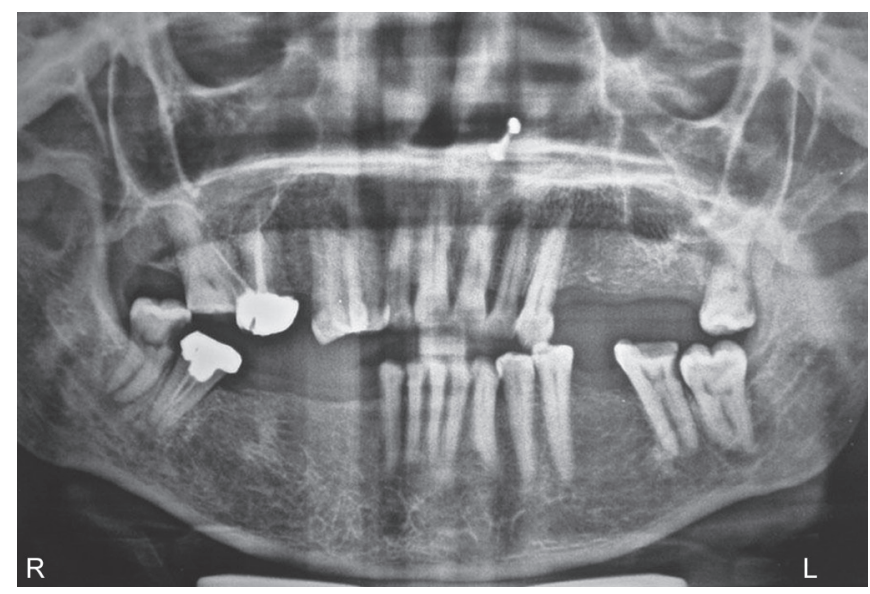

Fig. 7: Pretreatment panoramic X-ray to be done to maintain a fine balance between achieving a space for the opposing restorations and not compromising the structural integrity of the said teeth. The desired gingival alteration and associated osseous reduction for each tooth was calculated ${ }^{6}$ and the occlusal plane was corrected. Surgical guides were fabricated from the wax ups to aid in precision implant placement.

\section{Implant Placement}

Self thread-tapered implants[HI-TEC, LifeCare Devices] were placed in 12,13, and 14 region with simultaneous extraction of tooth no. 16 (Fig. 8). Two weeks later, implants were placed in 27, 29 , and 30 regions with simultaneous extraction of teeth nos. 31 and 32 (Fig. 9). All implants were placed following the delayed two-stage protocol.

\section{Crown Lengthening}

Crown lengthening with osseous resection was done for the upper right and lower left quadrants in two separate sittings two weeks apart. ${ }^{7}$ The amount of bone resected facially was approximately $1 \mathrm{~mm}$ on tooth no. 7; $2 \mathrm{~mm}$ on teeth nos. 6, 18, 20; and $3 \mathrm{~mm}$ on teeth nos. 3 and 5 (Figs 10 and 11). Teeth nos. 2 and 17 were extracted during the respective surgical procedures. Tooth no. 3 was prepared during the surgery, and barreling was done to provide acceptable periodontal sluiceways in the future.

\section{Endodontics}

Intentional root canal treatment ${ }^{8}$ was then carried out for teeth nos. $5,6,18$, and 20 . This was done to avoid any inadvertent damage to the pulp while over preparing these teeth occlusally to correct the occlusal plane.

\section{Restorative Work}

Restorative work was initiated three months after the crown lengthening procedure. After the second-stage surgery and adequate amount of healing time, upper and lower impressions were made for the implants with the open tray technique. A resin jig was prepared by the laboratory with the purpose of rechecking the alignment of the implants to each other and also to serve as a platform to make bite records. After adequate deprogramming, a centric relation record and a protrusive record was taken. The casts were mounted on a semi adjustable articulator with a face bow record. A diagnostic wax up was made on the necessary teeth

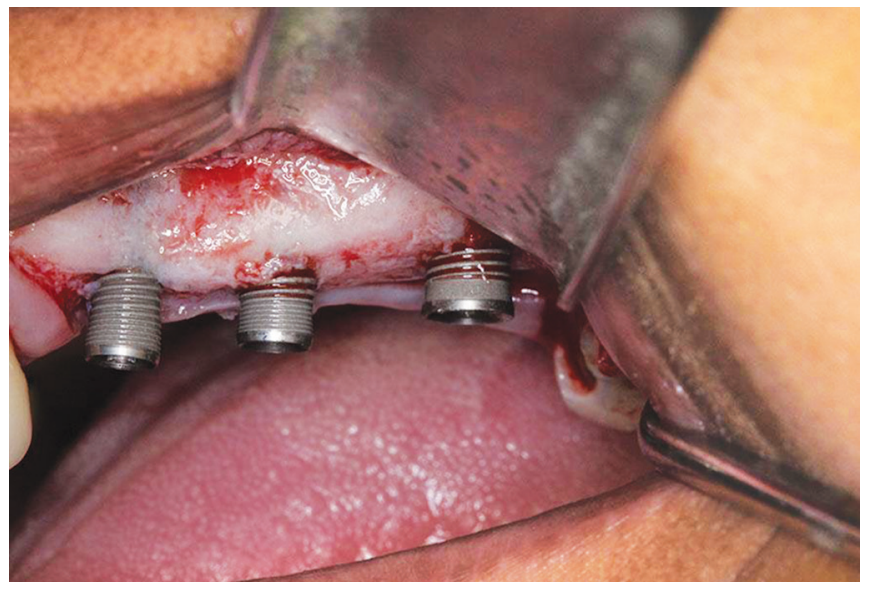

Fig. 8: Partially embedded implants in upper left quadrant depicting angulation and parallelism 


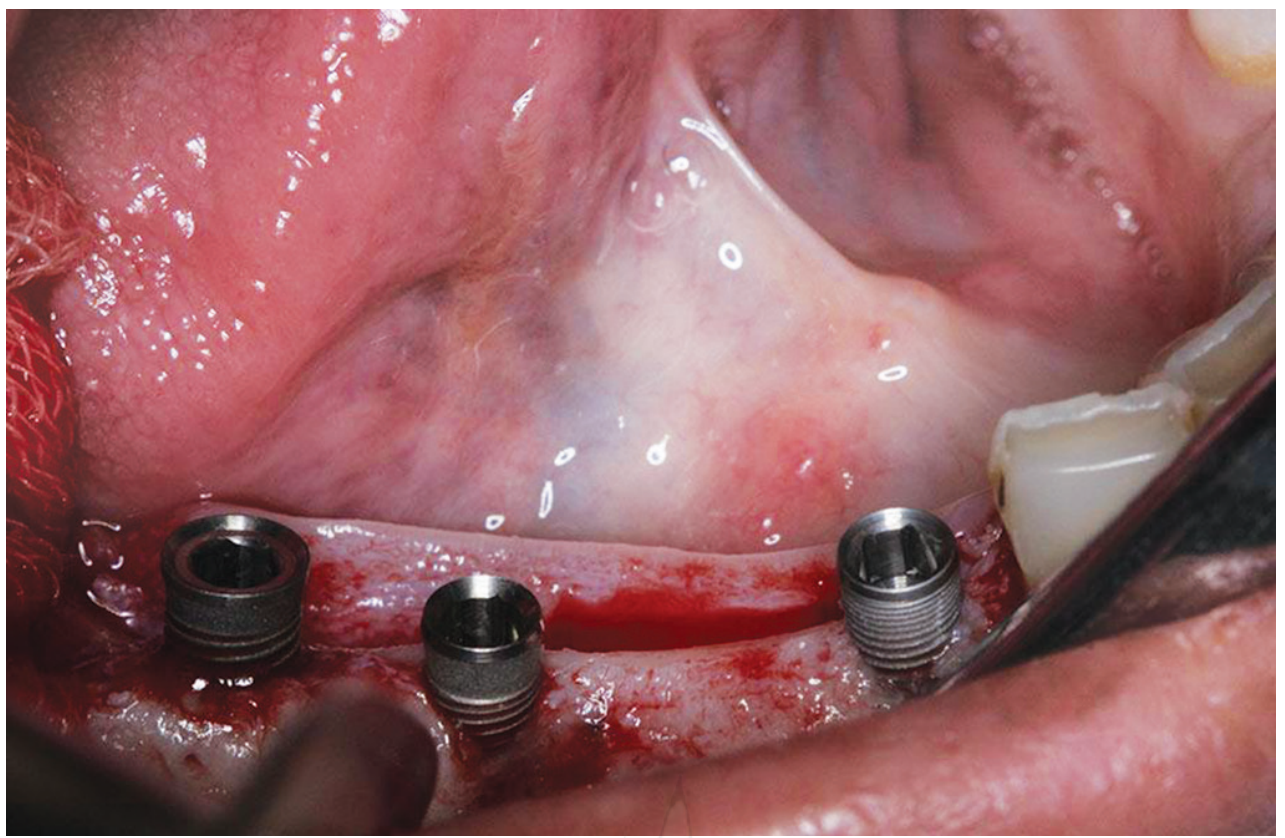

Fig. 9: Partially embedded implants in the lower right quadrant depicting angulation and parallelism

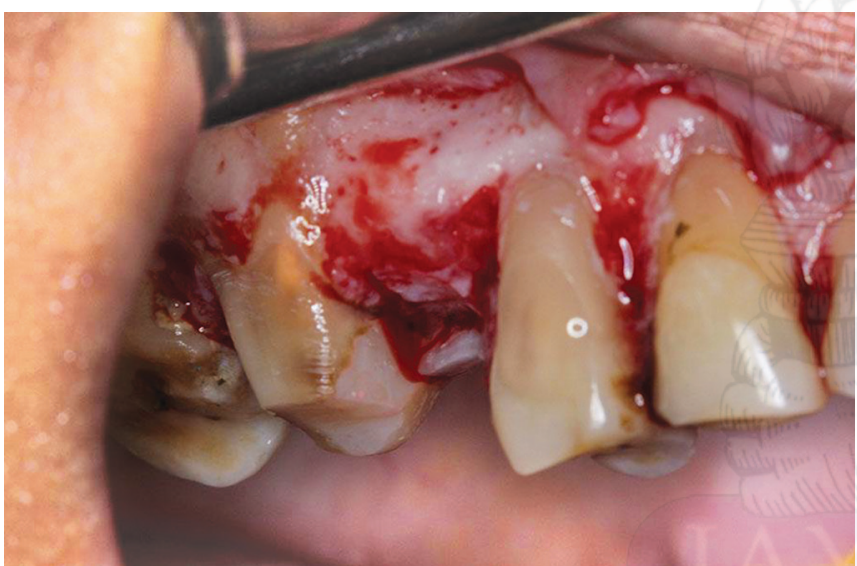

Fig. 10: Crown lengthening in the upper right quadrant with barreling of tooth no. 3

placing special emphasis on the development of occlusal scheme and a proper occlusal plane. A group function occlusion was developed so as to distribute the forces on the planned implant retained bridges. ${ }^{3}$

An addition silicone putty (3M ESPE Express STD) index of the wax ups was made and sectioned incisally and facially to aid in teeth preparations. The index was placed in the mouth periodically during teeth preparations to assess the clearance in the facial, incisal, and occlusal areas. Teeth nos. 3, 5, 6, 18, and 20 were prepared in accordance with the occlusal plane developed on the articulator. A little extra preparation was done in the cervical area of tooth no. 9 to accommodate the LCGV and allow some extra space for the ceramist during fabrication. ${ }^{9}$ This would ensure that this area does not eventually become a food trap, leading to periodontal problems. ${ }^{10}$ Margins were placed supragingival in all upper anterior teeth to avoid any potential complications in the extremely thin tissue biotype. ${ }^{11}$

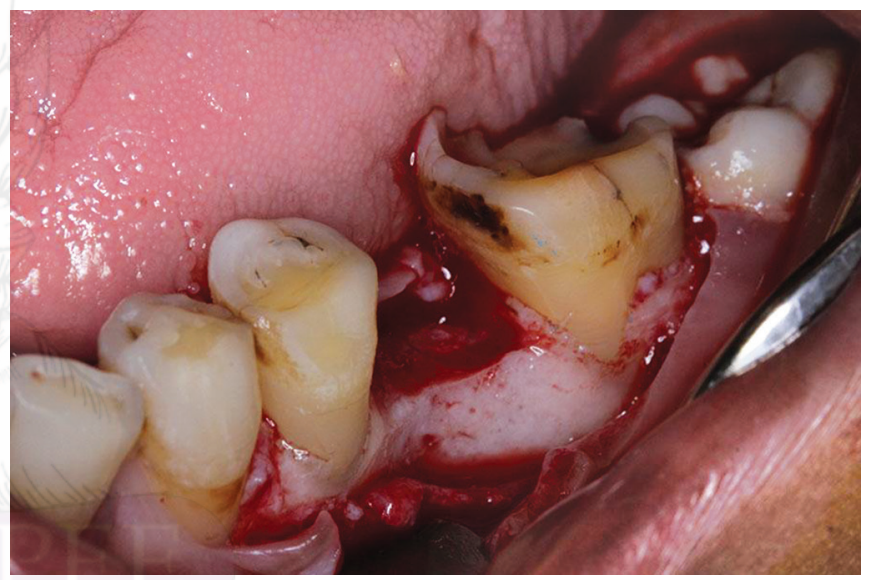

Fig. 11: Crown lengthening in the lower left quadrant

Another putty index was made and was used to fabricate direct provisional restorations (Protemp ${ }^{\mathrm{TM}} 43 \mathrm{M}$ ESPE) in the patient's mouth. The patient was asked to wear these provisional restorations for 2 weeks and some necessary adjustments were made to establish patient's esthetic needs. An impression of approved provisional restorations was made and sent to the laboratory to assist them in the fabrication of final restorations.

Final full arch impressions were made with polyether impression material (Impregum Penta ${ }^{\mathrm{TM}}$ with Pentamix ${ }^{\mathrm{TM}} 2$ Automatic mixing unit) on special custom-made trays following the open tray technique. Since the occlusion was now set in centric relation, it was easy to make bite records (Jet Bite, Coltene Whaledent). The posterior bite record was taken with the anterior provisionals in place. Anterior bite record was taken with posterior bite records in place, thus maintaining the established centric relation without altering the vertical dimension of occlusion. ${ }^{12}$ Then a face bow record was taken and the casts were mounted using the bite records taken. 


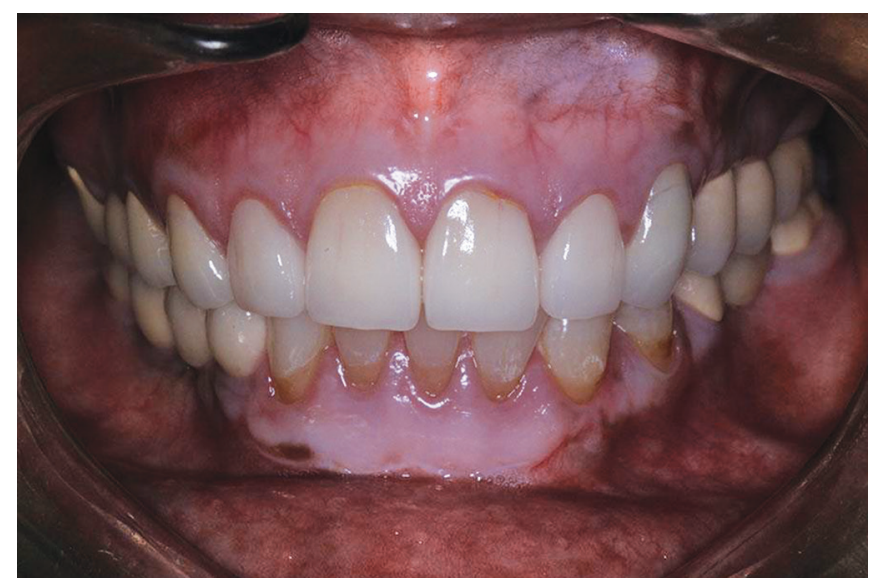

Fig. 12: A full frontal retracted view, posttreatment

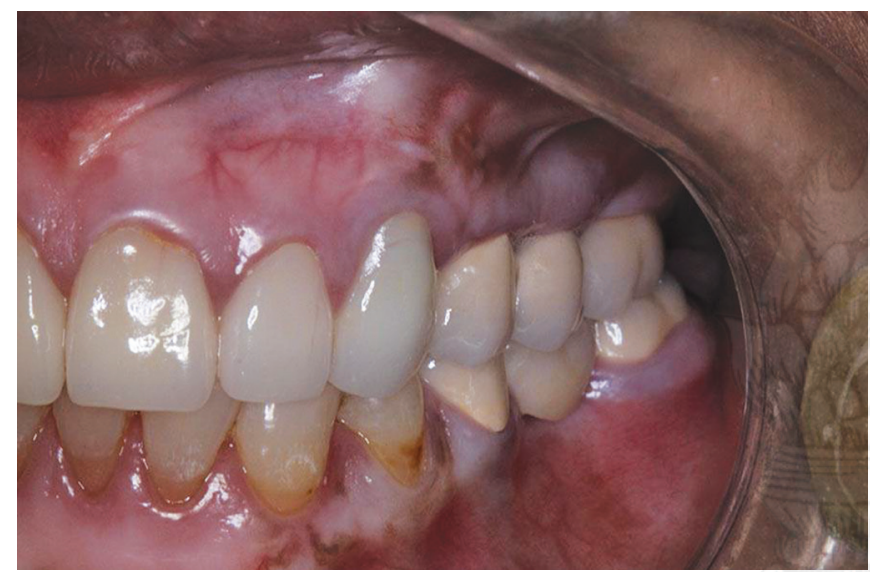

Fig. 14: A left lateral view showing achievement of restorative space, correction of occlusal plane, and gingival harmony

It was decided to fabricate traditional PFM restorations for the posterior teeth and E-max layered crowns [lvoclar Vivadent) for the upper anterior teeth (Figs 12 to 14). A screw retained splinted bridge was fabricated on the lower right side with tooth no. 28 being a pontic and a cement retained bridge was made on standard/ angulated abutments on the upper left side (Figs 15 and 16). The screws in the implant prosthesis were torqued to $30 \mathrm{~N} / \mathrm{cm}^{-2}$. The screw holes were blocked with putty and composite restoration was done to seal the access holes. Temporary cement [Freegenol GC Corporation, Tokyo, Japan] was used to cement the bridge on the upper left implants. Regular three unit bridges were fabricated from tooth nos. 3-5 and 18-20.

The ceramist was asked to give special emphasis on maintaining the seamless transition of crown to margin on tooth no. 9 with LCVG (Fig. 17) and fluting was done on retainer of tooth no. 3. Occlusion and anterior guidance was checked and refined before cementation. The posterior teeth were cemented with glass ionomer luting cement [GC Fuji 1, GC corporation, Tokyo, Japan] and E-max crowns were cemented using dual cure resin cement [Variolink N, Ivoclar Vivadent] following the standard cementation and adhesive protocols.

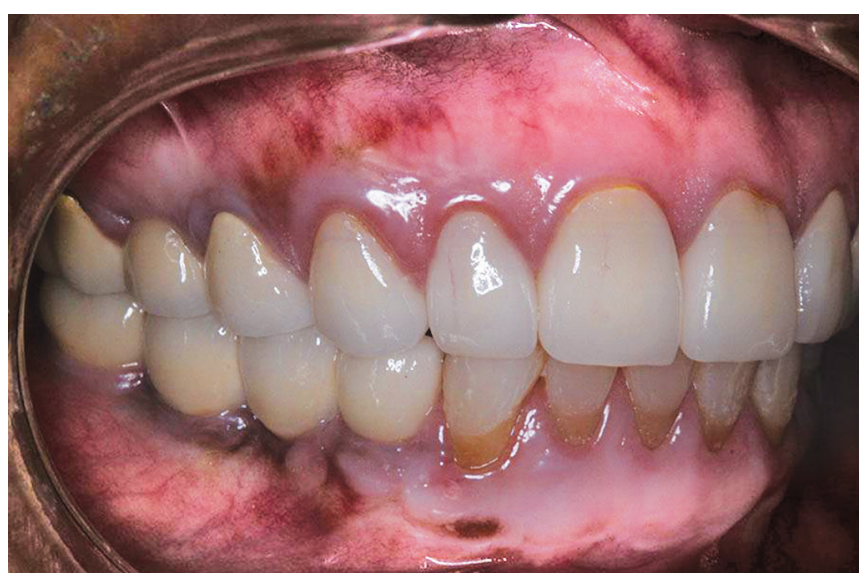

Fig. 13: A right lateral view showing achievement of restorative space, correction of occlusal plane, and gingival harmony

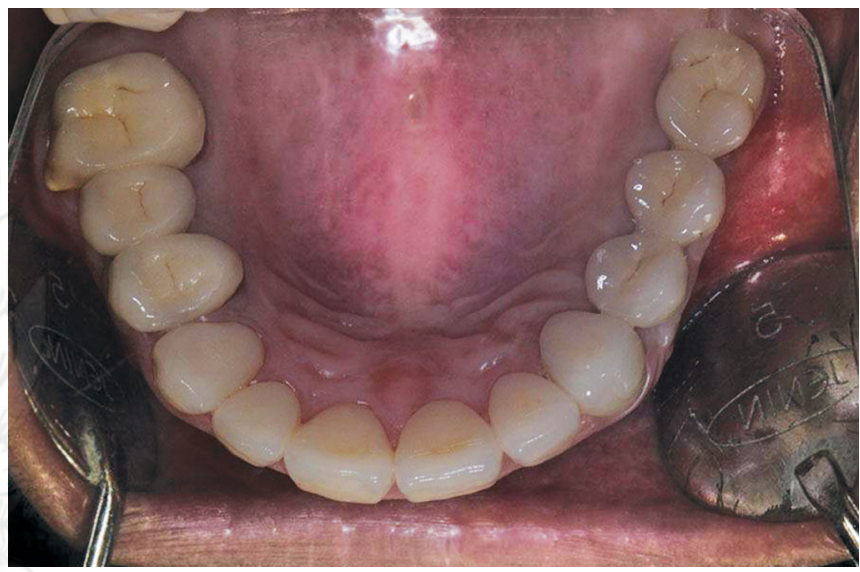

Fig. 15: Maxillary occlusal view, posttreatment

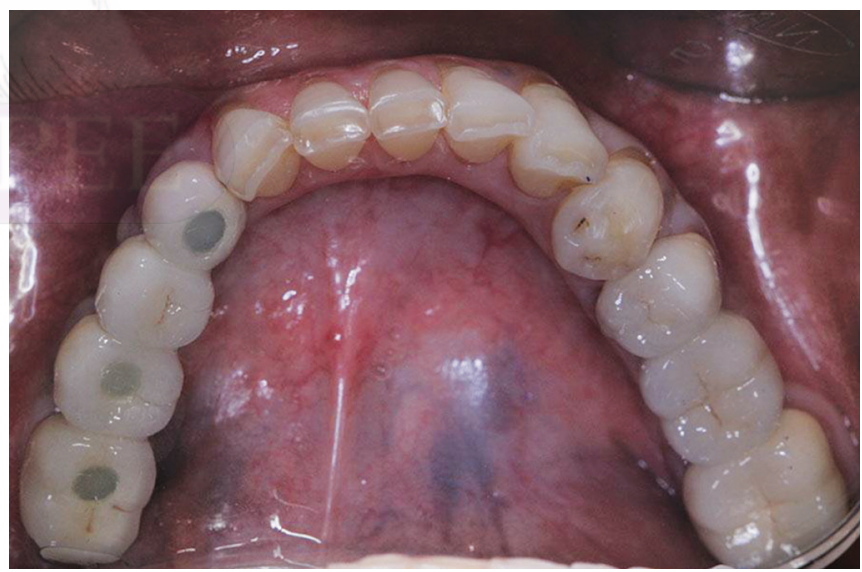

Fig. 16: Mandibular occlusal view, posttreatment

\section{Biotype Conversion}

A month after the restorations, it was deemed fit to convert the biotype in the lower anterior segment to deal with recession. This was done after the restorative phase to ensure that the anterior teeth had no trauma from occlusion owing to missing posterior 


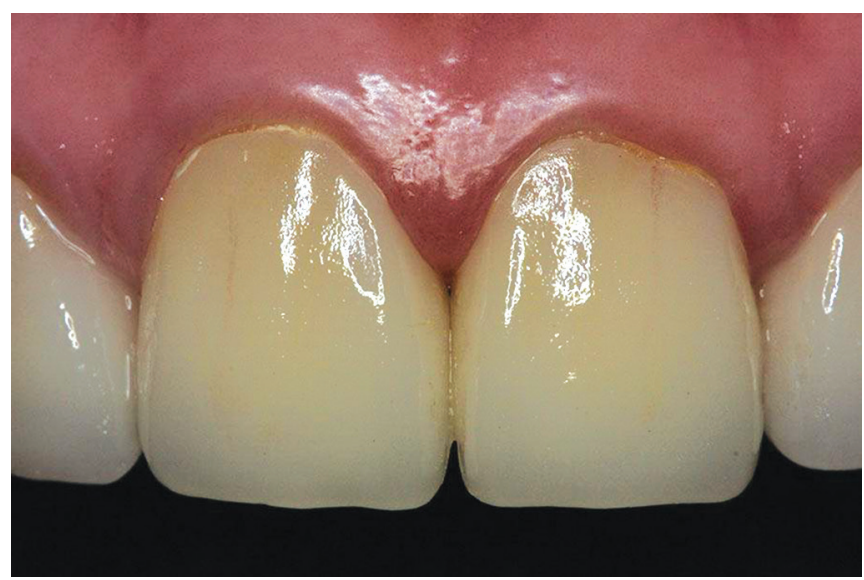

Fig. 17: Supragingival margins. Seamless transition of crown to margin on tooth no. 9 with the LCVG

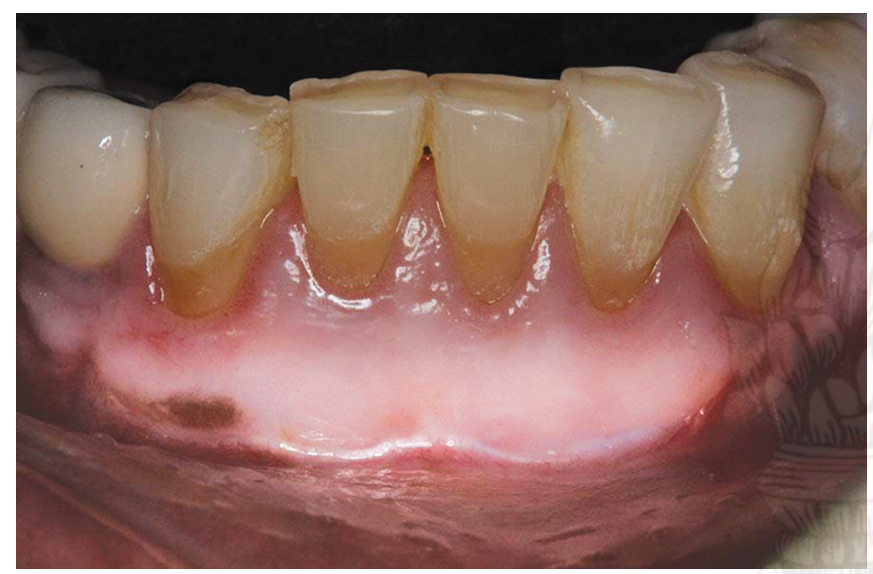

Fig. 19: Adequate keratinized tissue enabling maintenance of oral hygiene

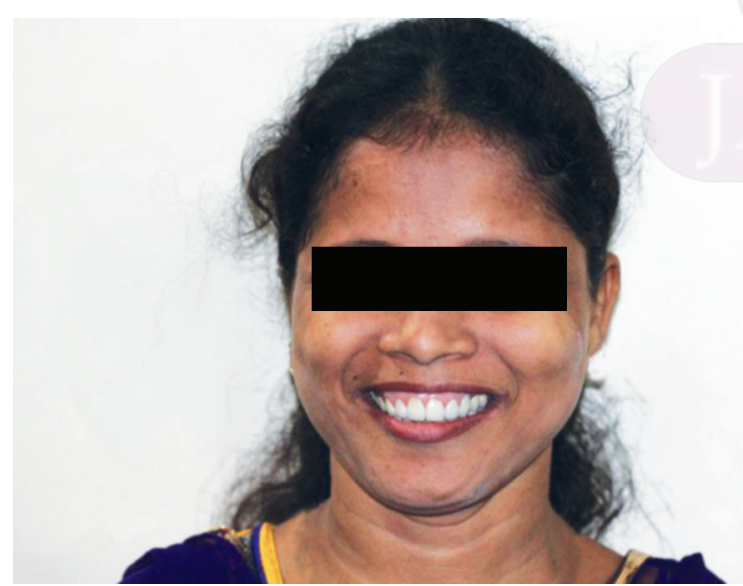

Fig. 21: Full face, posttreatment, showing signs of nourishment

teeth. ${ }^{13}$ A split thickness flap was raised in the area from teeth no. 22-26 and the epithelium was excised. Any residual tissue tags were removed with tissue nippers to create a uniform recipient bed. Thorough root planing was done to remove the smear layer and the root surface was treated to tetracycline treatment. A free gingival graft was then taken from the right as well as the left side

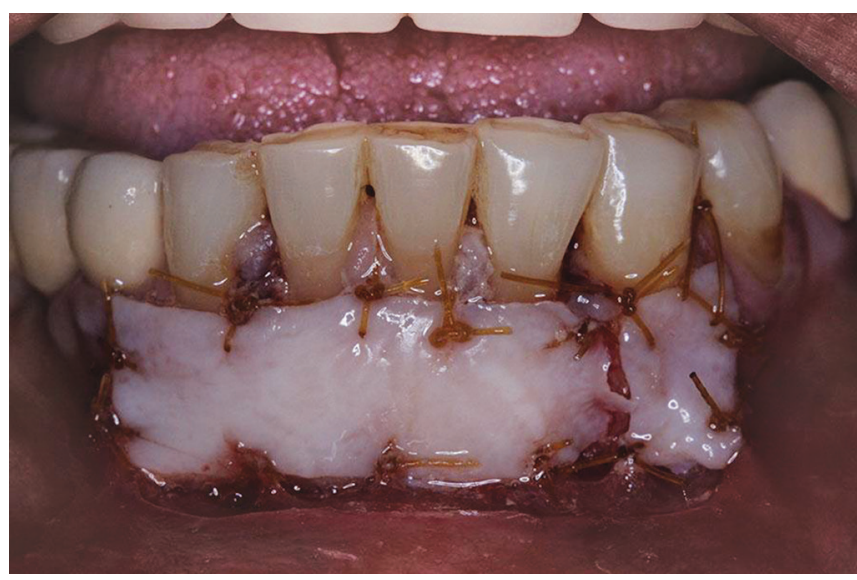

Fig. 18: Free gingival graft

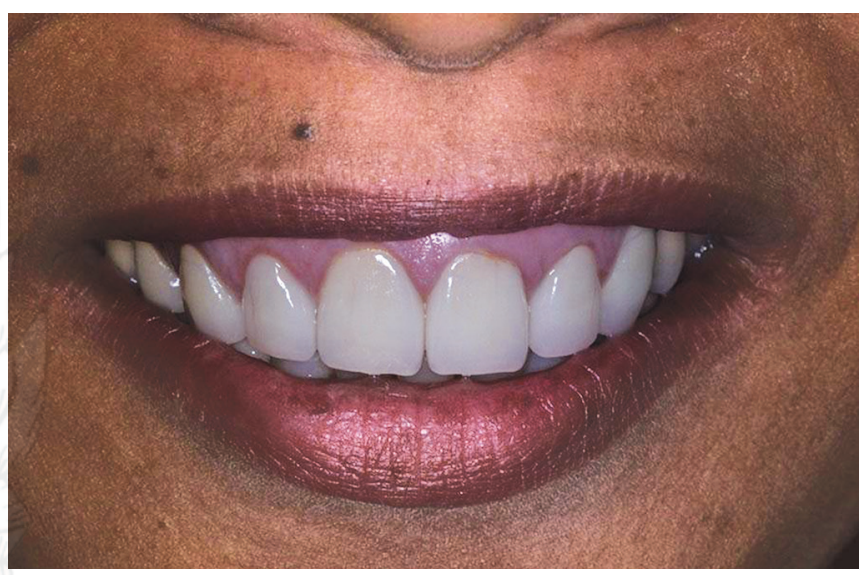

Fig. 20: Full smile, posttreatment

of the palate and sutured at the recipient site. 4-0 absorbable sutures [Mersutures, Ethicon] were given coronally, apically, and laterally ${ }^{14}$ (Fig. 18). Necessary instructions were given to the patient for postoperative care. The graft took up very well, providing adequate keratinized tissue, thus enabling the patient to maintain her oral hygiene (Fig. 19).

\section{Conclusion}

With a dearth of restorative space, the first instinct of a restorative dentist is to raise the bite. Increasing the vertical dimension has been a debatable topic for decades. ${ }^{15}$ The primary concern is that it may lead to an undue stress on the entire masticatory apparatus. ${ }^{3}$ Secondly, it might not meet the overall facial esthetic criteria. Lastly, this approach would necessitate restorations on all teeth, thus leading to preparations on few virgin teeth, which are otherwise perfect. Crown lengthening in addition to providing space also ensures correction of occlusal plane caused owing to supraeruption. Achieving an ideal occlusal scheme should not entail unnecessary destruction of sound teeth ${ }^{16}$ [like teeth no. 21-26]; rather a pragmatic approach should be adhered to as closely as possible.

The complex nature of such cases should not distract a clinician from paying attention to other minutiae such as restorative details on tooth no. 3 and 9, so as to maintain long-term harmony in these young patients. 
Such patients are usually low in self-esteem and undernourished. A pragmatic approach ensured that the patient had a new smile (Fig. 20), leading to an increase in self confidence. Regular nourishment, post full mouth rehabilitation led to an increase in the overall weight of the patient (Fig. 21).

\section{ACKNOWLedgments}

The author acknowledges the persistent motivation by $\mathrm{Dr}$ Devyani Wagle who assisted him in several procedures. He also acknowledges the fine ceramic artistry by Danesh Vazeefdar from Adaro Dental Lab, Mumbai.

\section{References}

1. Craddock H, Youngson CC, Manogue $M$, et al. Occlusal changes following posterior tooth loss in adults. J Prosthodont 2007;16(6): 485-494. DOI: 10.1111/j.1532-849X.2007.00212.x.

2. Kois JC. Diagnostically driven interdisciplinary treatment planning. Cohen M. Interdisciplinary Treatment Planning: Principles, Design, Implementation, 1st ed., Chicago IL: Quintessence Publishing; 2008.

3. Dawson PE. Functional occlusion: From TMJ to Smile Design. St. Louis, MO: Mosby; 2006.

4. Mass $E$, Aharini $K$, Vardimon AD. Labial-cervical-vertical groove in maxillary permanent incisors- prevalence, severity and affected soft tissue. Quintessence Int 2005;36:281-286.

5. Takana-Yamamato T, Kuroda S. Titanium screw anchorage for correction of canted occlusal plane in patients with facial asymmetry. Am J Orthod Dentofacial Orthop 2007 Aug;132(2):237-426. DOI: 10.1016/j.ajodo.2005.12.032.
6. Allen EP. Use of mucogingival surgical procedures to enhance esthetics. Dent Clin North Am 1988;32(2):307-330.

7. Bateman GJ, Karir N, Saha S. Principles of crown lengthening surgery. Dent Update 2009, Apr;36(3):181-182, , 184-185, 10.12968/ denu.2009.36.3.181.

8. Bohannan HM, Abrams L. Intentional pulp extirpation in periodontal prosthesis. J Prosthet Dent 1961;11:781. DOI: 10.1016/0022 3913(61)90187-1.

9. Gracis S, Fradeani M, Celletti R, et al. Biological integration of esthetic restorations: Factors influencing appearance and long-term success. Periodontology 2000 2001;27:29-44. DOI: 10.1034/j.16000757.2001.027001029.x.

10. Kois JC. The restorative - periodontal interface: biological parameters. Periodontology 2000 1996;11(1):29-38. DOI: 10.1111/j.1600-0757.1996. tb00180.x.

11. de Waal $\mathrm{H}$, Castellucci $\mathrm{G}$. The importance of restorative margin placement to the biologic width and periodontal health. Part II. Int J Periodontics Restorative Dent 1994;14(1):70-83.

12. Lerner J. A systematic approach to full - mouth reconstruction of the severely worn dentition. Pract Proced Aesthet Dent 2008;20(2): $81-87$.

13. Ustan K, Sari Z, Orucoglu H, et al. Severe gingival recession caused by traumatic occlusion and mucogingival stress: A case report. Eur J Dent 2008, Apr;2:127-133.

14. Anthony S. Soft tissue and esthetic considerations in implant therapy. Quintessence Publishing Co, Inc; 2003. pp. 123-129.

15. Spear FM. Approaches to vertical dimension. Adv Esthet Interdiscip Dent 2006;2(3):2-12.

16. Kelleher M. Introducing the concept of pragmatic esthetics, with special reference to the treatment of tooth wear. J Esthet Restor Dent 2011;23(5):1-17. 